\title{
Endoscopic submucosal dissection of a lateral spreading tumor involving the appendiceal orifice using a multi-traction device.
}

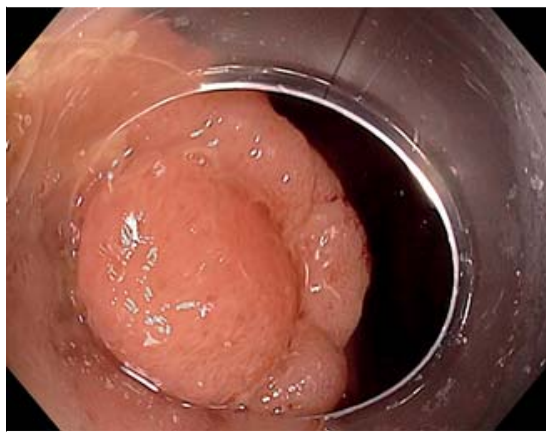

Fig. 1 A granular lateral spreading tumor invading the previous site of appendectomy.

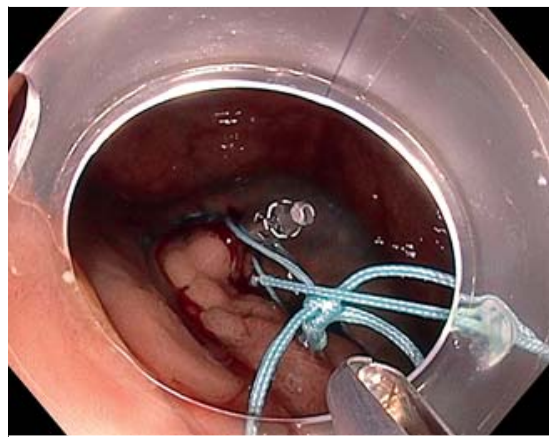

- Fig. 2 The submucosal space was well exposed at the two edges of the granular lateral spreading tumor thanks to the multi-traction device.

Endoscopic submucosal dissection (ESD) is the technique of choice for the resection of large superficial colorectal lesions [1], but it can be technically challenging in some situations. For this reason, lesions involving the appendiceal orifice have long been removed surgically. However, recent findings have found that ESD is effective and safe in that situation [2, 3], even for lesions deeply invading the appendiceal orifice (Toyonaga 3 lesions) with the help of traction device $[4,5]$.

Here we report the case of a 70-year-old woman with a history of appendectomy who underwent a colonoscopy that revealed a granular lateral spreading tumor (LST-G) of $3 \mathrm{~cm}$ invading the pre-

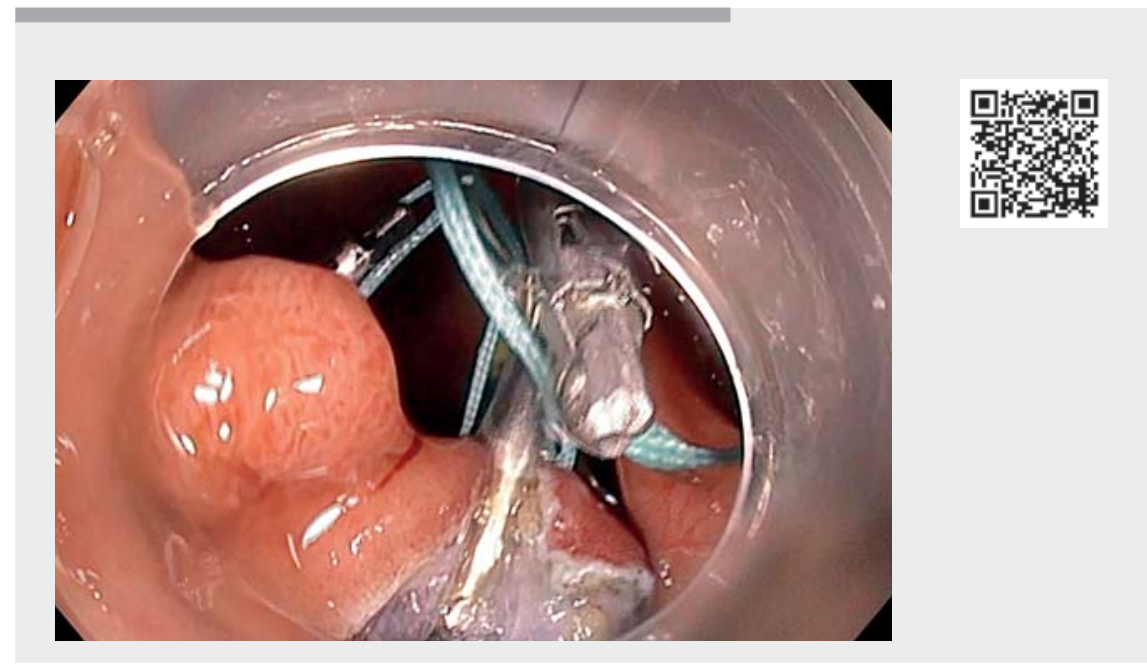

$\checkmark$ Video 1 Endoscopic submucosal dissection of a lateral spreading tumor involving the appendiceal orifice using a multi-traction device.
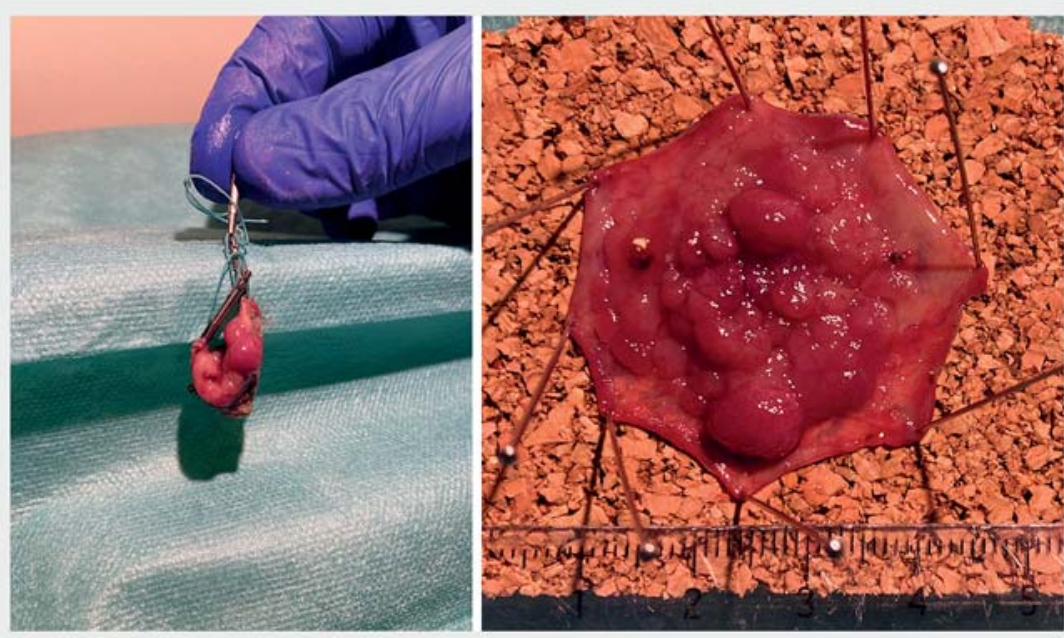

Fig. 3 Lesion after resection.

vious site of the appendectomy (Toyonaga 3a) (> Fig. 1). An ESD using a multi-intertwined loop device was chosen ( Video 1). After circumferential mucosal incision around the lesion, the first loop of the device was attached to one edge of the lesion with a hemostatic clip. Then a second loop was attached to the opposite edge of the lesion. Then the entire device was attached to the opposite colonic wall. The submucosal space was well exposed at the two edges of the LST-G, allowing a safe dissection during the whole procedure with an en-bloc resection ( $>$ Fig. 2 , \Fig. $\mathbf{3}$ ). The patient was discharged the day after without 
experiencing any adverse event. The pathology report showed a high-grade dysplasia with a focus of intramucosal adenocarcinoma that was completely resected by the ESD. Owing to the curative resection, an endoscopic follow-up was decided.

This case highlights that ESD can be safely performed in the appendiceal orifice even with a history of appendectomy. The use of a multi-traction device helped to obtain very satisfying exposure of the submucosal space. A randomized control study evaluating this device would be necessary to confirm this promising result.

Endoscopy_UCTN_Code_TTT_1AQ_2AJ

\section{Competing interests}

The authors declare that they have no conflict of interest.

The authors

Thomas Lambin ${ }^{1,2}$, Jérémie Albouys ${ }^{3}$, Clara Yzet $^{4}$, Soline Brun ${ }^{1}$, Florian Rostain ${ }^{1}$, Jérôme Rivory ${ }^{1}$, Mathieu Pioche ${ }^{1,2}$

1 Gastroenterology and Endoscopy Unit, Pavillon L, Edouard Herriot Hospital, Lyon, France
2 Inserm U1032, Labtau, Lyon, France

3 Gastroenterology and Endoscopy Unit, CHU Dupuytren, Limoges, France

4 Department of Gastroenterology, Amiens University Hospital, Amiens, France

Corresponding author

\section{Thomas Lambin, MD}

Endoscopy Unit - Digestive Disease Department, Pavillon L - Edouard Herriot Hospital, 69437 Lyon Cedex, France thomaslambin@hotmail.fr

\section{References}

[1] Pimentel-Nunes P, Dinis-Ribeiro M, Ponchon T et al. Endoscopic submucosal dissection: European Society of Gastrointestinal Endoscopy (ESGE) Guideline. Endoscopy 2015; 47: 829-854

[2] Jacob H, Toyonaga T, Ohara Y et al. Endoscopic submucosal dissection of cecal lesions in proximity to the appendiceal orifice. Endoscopy 2016; 48: 829-836

[3] Tashima T, Ohata K, Nonaka K et al. Endoscopic submucosal dissection for laterally spreading tumors involving the appendicea orifice. Surg Endosc 2017; 31: 5444-5450

[4] Oung B, Rivory J, Chabrun E et al. ESD with double clips and rubber band traction of neoplastic lesions developed in the appendiceal orifice is effective and safe. Endosc Int Open 2020; 08: E388-E395
[5] Jacques ], Charissoux A, Legros R et al. Double-clip counter-traction using a rubber band is a useful and adaptive tool for colonic endoscopic submucosal dissection. Endoscopy $2018 ; 50: 179-181$

Bibliography

Endoscopy 2022; 54: E425-E426

DOI 10.1055/a-1581-7411

ISSN 0013-726X

published online 8.9 .2021

(c) 2021. Thieme. All rights reserved.

Georg Thieme Verlag KG, Rüdigerstraße 14, 70469 Stuttgart, Germany

\section{ENDOSCOPY E-VIDEOS \\ https://eref.thieme.de/e-videos}

回回 Endoscopy E-Videos is an is open access online section, 回艘: reporting on interesting cases and new techniques in gastroenterological endoscopy. All papers include a high quality video and all contributions are freely accessible online. Processing charges apply (currently EUR 375), discounts and wavers acc. to HINARI are available.

This section has its own submission website at https://mc.manuscriptcentral.com/e-videos 